\title{
Use of different magnification factors to calculate radiological lung volumes
}

\author{
A BUSH, DM DENISON \\ From the Lung Function Unit, Brompton Hospital, London
}

In previous papers from this laboratory, Pierce et al described a method of measuring lung volumes from routine chest radiographs. ${ }^{12}$ The images on the film are magnified, and this was taken into account in their calculations. Their findings have recently been confirmed by Rodenstein et al. ${ }^{3}$ It is important to measure magnification accurately because errors in linear dimensions are cubed when volume is calculated. This paper describes two simple methods of improving the accuracy of the calculation of magnification.

\section{Methods}

\section{STUDY 1: IMPROVED FORMULA USING SYSTEM} GEOMETRY

The method of calculating magnification from system geometry as used by Pierce et al is shown in figure 1. The maximum anteroposterior diameter of the thorax $(2 \times \mathrm{I}, \mathrm{fig} 1)$ is unknown, but is assumed to be the same as the maximum anteroposterior image in the lateral chest radiograph. Clearly this image will also be magnified. This assumption can be removed by modifying the equations in such a way that $M A=D /(D-d-O L / 2)$ and $M L=D /(D-d-O A / 2)$, where $M A, M L$ are magnifications for posteroanterior and lateral films respectively; $O A, O L$ are the maximal posteroanterior and lateral diameters of the object (all unknown); $D$ is the tube-film distance and $d$ the size of the air gap between the subject and the film. Also by definition $M A$ $=I A / O A$ and $M L=I L / O L$, where $I A, I L$ are the maximal image sizes in the posteroanterior and lateral films (measured manually from the films). These four linear simultaneous equations can be solved for the magnification factors, giving

$$
\begin{gathered}
M A=\frac{4 D^{2}-I A . I L}{2(d . I L+D(2 D-2 d-I L))} \text { and } \\
M L=\frac{4 D^{2}-I A . I L}{2(d . I A+D(2 D-2 d-I A))}
\end{gathered}
$$

We investigated the importance of this modification by comparing the measured total lung capacity (TLC) from 40 chest radiographs using the new and old formulae, with TLC determined by whole body plethysmography. ${ }^{4}$ Twenty radiographs were taken at a tube-film distance of $3 \mathrm{~m}(10 \mathrm{ft})$ and another 20 radiographs at a distance of $1.8 \mathrm{~m}(6 \mathrm{ft})$. The

Address for correspondence: Dr A Bush, Lung Function Unit, Brompton Hospital, London SW3 6HP.

Accepted 9 September 1985 subjects were healthy people having chest radiographs for routine screening. The films for this and the second study were digitised exactly as described by Pierce $e t a l$, and the different calculated magnification factors were applied to the same digitisation.

STUDY 2: COMPARISON OF SCALING OBJECTS WITH SYSTEM GEOMETRY

Pierce et al suggested that scaling objects such as coina should be taped to the front and back of the subject if the system geometry was not known-for example, when takingo portable chest radiographs. Magnification, however, does not vary linearly from front to back and the mean of the magnification of the two coins is not the same as that calcuo lated geometrically. Magnification derived from coins would be more comparable to that from system geometry if tho coins were taped to the side of the object, half way between front and back. We investigated the importance of this in 18 subjects who had radiographs taken at a tube-film distance of $3 \mathrm{~m}$ with two coins taped front and back, as suggested b? Pierce, and two coins at the side, as suggested by us. The positions of the coins at the midpoint of the lateral aspect of the thorax were estimated by eye. Two coins were used to minimise errors caused by incorrect positioning.

\section{Results}

All the results were shown to be normally distributed by the Kolmogorov-Smirnov test using the sample means and stang dard deviations as an estimate of those of the population and therefore all comparisons were done with paired $t$ test

STUDY 1

There was good agreement between plethysmographic TL and radiographic TLC for the films taken at $3 \mathrm{~m}$, whichevey magnification was used. Pierce's formula underestimated TLC by $48 \mathrm{ml}$ (standard deviation of the difference (SDDZ $139, \mathrm{NS}$ ) and the new formula underestimated TLC by $5 \mathrm{ndW}$ (SDD 139, NS). For the $1.8 \mathrm{~m}$ films, however, the Pierce formula leads to an underestimate of $321 \mathrm{ml}$ (SDD 572 $\mathrm{p}<0.05$ ), whereas the new formula leads to an undef estimate of $133 \mathrm{ml}$ (SDD 523, NS). The individual results at plotted in figure 2 .

STUDY 2

We compared the TLC calculated with the new formuf based on system geometry with that calculated from medi surement of coins placed at the front and back and at the 


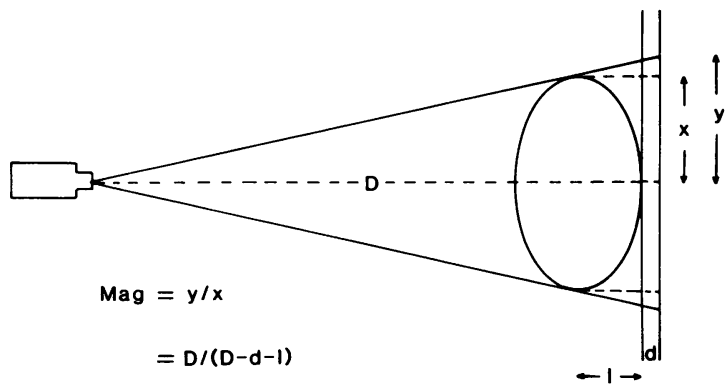

Fig 1 Principles of estimation of magnification factors from tube-film distance (D), air gap between subject and film (d), and half chest diameter (I) measured from a radiograph taken in the other projection.
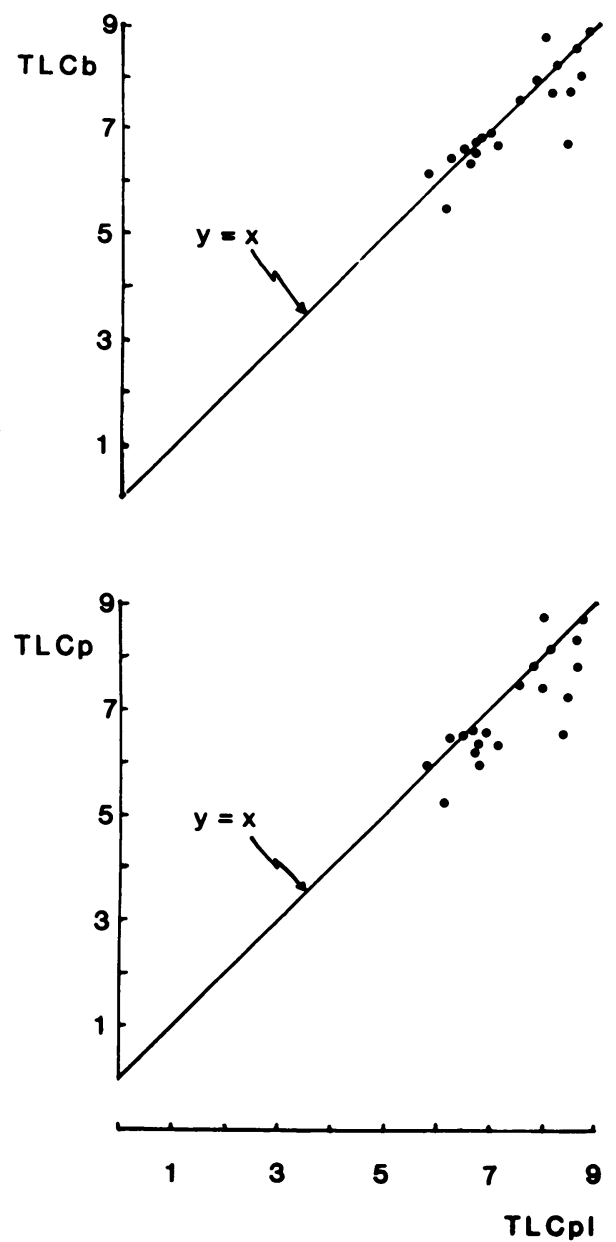

Fig 2 Comparison of difference between plethysmographic $T L C$ (TLCpl) and TLC measured from system geometry using the new (TLCb) and old (TLCP) formulae (all volumes given in litres). sides. There was good agreement between geometric TLC and TLC calculated on the basis of method of placing coins (mean underestimate $36 \mathrm{ml}$, SDD 89, NS). With Pierce's method, however, the underestimate was greater (mean $195 \mathrm{ml}, \mathrm{SDD} 133, \mathrm{p}<0.002$ ). The difference between results of the two methods of placing the coins was significant $(p<$ 0.01 ).

\section{Discussion}

In a previous paper a formula for calculating magnification from system geometry was given. We have now shown that this formula can be improved quite simply. At a tube-film distance of $3 \mathrm{~m}$ no important advantage is introduced, but at shorter distances the advantage becomes more important, correcting a mean underestimate of $4 \%$ at $1.8 \mathrm{~m}$.

If system geometry is not known, magnification can be found from scaling objects. The inclusion of scaling objects is not, however, a wholly simple matter even for the system of marker discs that we advocated previously. We propose a straightforward modification of the technique that uses marker discs in section. The modification improves the accuracy of measurement by $3 \%$ in our 10 subjects, and gives results that are as accurate as those obtained with system geometry. Furthermore, discs placed in section will not obscure any important clinical detail.

To summarise, radiographic measurement of lung size requires accurate knowledge of magnification, which can be obtained with equal precision either by calculation from the system's geometry or by the inclusion of scaling objects of known size. The choice of method is dictated by convenience alone. Scaling objects have the advantage that the magnification record is implicit in the film, and so the details of system geometry do not need to be stored separately. We have proposed modifications that have improved the accuracy of the previous $\operatorname{method}^{1}$ by up to $4 \%$. These modifications are particularly important at short tube film distances.

We are grateful to Dr D Stanescu, who provided the films taken at $1.8 \mathrm{~m}$ and the corresponding plethysmographic data.

\section{References}

1 Pierce RJ, Brown DJ, Holmes M, Cumming G, Denison DM The estimation of lung volume from chest radiographs using shape information. Thorax 1979;34:726-34.

2 Pierce RJ, Brown DJ, Denison DM. Radiographic, scintigraphic and gas-dilution estimates of individual lung and lobar volumes in man. Thorax 1980;35:773-80.

3 Rodenstein DO, Sopwith T, Denison DM, Stanescu D. A reevaluation of the radiographic method for the measurement of total lung capacity. Bull Eur Physiopath Respir (in press).

4 Du Bois AB, Botelho SY, Bedell GN, Marshall R, Comroe JH. A rapid plethysmographic method for measuring thoracic gas volume: a comparison with a nitrogen washout method for measuring functional residual capacity in normal subjects. $J$ Clin Invest 1956;35:322-6.

5 Siegel S. Nonparametric statistics. Tokyo: McGraw Hill, Kogakusha, 1956:47-52. 